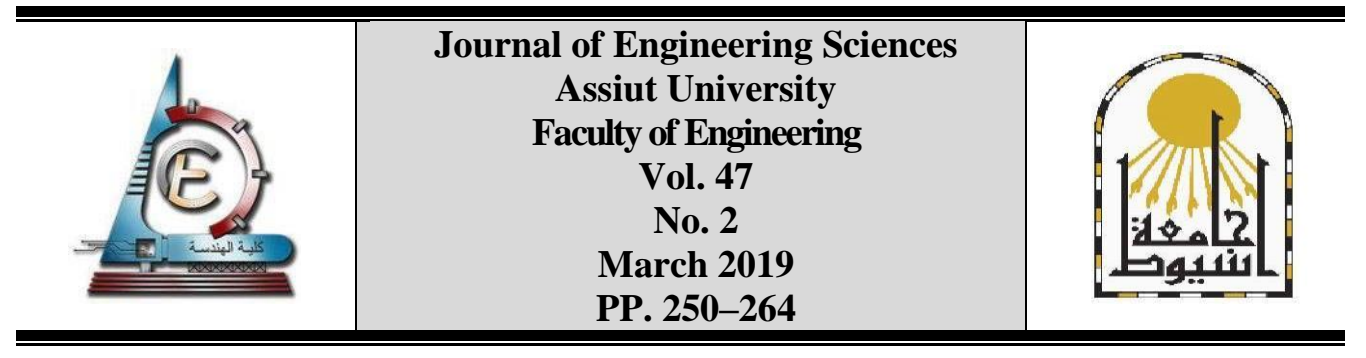

\title{
THE ROLE OF THE ARCHITECT IN CHOOSING SUSTAINABLE UNITS TO RESTRICT FRESH WATER ABUSE IN NEW URBAN COMMUNITIES - Case study " NEW CAIRO"
}

\author{
Ebtehal Galal EI Deen Mohamed
}

Architecture Department, Faculty of Engineering -Matarya, Helwan University

Received 10 December 2018; Accepted 30 December 2018

\begin{abstract}
In terms of the significance of the role of Architects in resolving mega problems in the Engineering practice in the various fields, this study was initiated to investigate the implementation of architectural practice to restrict fresh water abuse by reducing surplus water consumption in new urban communities, where New Cairo was taken as a case study. Primarily, literature was reviewed in the field of water consumption and water resources. In addition, objectives were set, upon which a research methodology was planned. The planned methodology is based on a descriptive analytical approach, where an electronic questionnaire was designed and distributed among a random sample in New Cairo in order to survey their perception to water consumption. Moreover, a statistical analysis was achieved to the random population answers, where graphs and tables were produced using SPSS software. Finally, conclusions were deduced that proposed simple affordable tools in new cities in order to ensure efficient water consumption and reduce the surplus water misuse in new urban communities. This would most probably ensure reliable water supply to the present generation and safeguard it to the future ones. In addition, recommendations for future research and Engineering practice were suggested.
\end{abstract}

Keywords: Saving water, Water security, Flow rate, New Cairo.

\section{Introduction}

The role of Architects is of great significance in the Engineering Practice, as they resolve mega problems in various fields, especially in the fields of energy and water consumption so as heat transfer, by introducing simple affordable or tools. Reducing water consumption, as a core of sustainable development integrating ecosystem to human survival, is of great significance. It is one of the most important global challenges and sustainable development, which could be achieved by improving water consumption efficiency.

In the same framework, water misuse created an unprecedented pressure on water resources, as estimates reflected that if practices remain unchanged, the world will face water shortage. (i.e. Estimates pointed out to $40 \%$ by 2030 . Foreseen is that nine billion are required to be nourished by 2050 by increasing the agricultural productivity by $60 \%$ ), which consumes $70 \%$ of water cycle, globally; meanwhile, groundwater is depleting at a faster rate than recharge, which signposts that by 20251.8 billion will suffer scarcity [1]. 
In terms of the importance of Architects contribution in the Engineering practice, this study was commenced in order to investigate architectural role to reduce surplus water consumption in New Cairo, as a case study representing new urban communities.

The research methodology was designed to be based on a descriptive analytical approach, where data was assembled via a theoretical study by reviewing the previous studies in that field. In addition, it was assembled via an electronic questionnaire that was distributed among a random sample in order to survey water consumption awareness. Moreover, statistical analysis was carried out and graphs so as tables were produced. This paper elaborates the achieved investigation under the subsequent headlines, as follows:

\section{Literature review}

Many studies were achieved to signpost the importance of the Architect role in contributing in resolving mega problems in the Engineering Practice, in the global, regional and local zones, are involved in water studies. Among these studies are [1-5, 713]. This is elaborated as follows:

Regarding the Global Studies [1] , the World Bank published a report in July 2016 about water scarcity impaired by climate change, which would most probably lead to land loss that would mount to $6 \%$ of Gross Domestic Product GDP. This will stimulate migration and fuel conflicts. In addition, the combined effects of population growth, rising income and urbanization will lead to an increase in water demand, while supply will remain irregular and uncertain.

- As for the Regional Studies, the 2015 World Economic Forum reflected that the Middle East and North Africa (MENA) [2], Middle East and Egypt in particular, are least prepared to water crises; Fig. 1. In addition, the Figure. Indicated that over $60 \%$ of the region's population lives in areas of water stress, which is very high, compared to the average world of $35 \%$. This indicates the water stress threatening the region. However, the main challenge to the region development is to take necessary actions in order to navigate in sustainable paths towards safe water. Despite water scarcity, the Middle East and North Africa have the lowest water tariffs in the world; Fig. 2 and the average service cost is twice the average service charge. This might lead to excessive use of scarce water resources. Moreover, economic losses of 4 to 16\% of Gross Domestic Product GDP are evident by 2050.

- Concerning the Local Studies, some investigations elaborated that the Nile supplies $80 \%$ of water resources, in Egypt, followed by ground water, rain and floods. Agriculture consumes $78 \%$ of this water, then drinking water and then industry; Fig.3,4. Such studies emphasized that water scarcity declines the per capita Gross Domestic Product GDP to reach 860 cubic meters by 2002, while it was $1712 \mathrm{~m}^{3}$ in $1970,2604 \mathrm{~m}^{3}$ in 1940. This indicated that Egypt relocated itself from water abundance to sufficient water in 1970. Then it turned to water scarcity at the beginning of 1996 [3]. It is expected to increase its scarcity with upstream dam projects that would influence future local production per capita. World Health Organization documented that basic drinking water services distribution was 99.30\% urban and rural 97.64\%, in 2015 [4] . However, Cairo's fresh water tariff was 0.05 dollars, while $2 \%$ of GDP is expended on other services. This might lead to an excessive water misuse. 


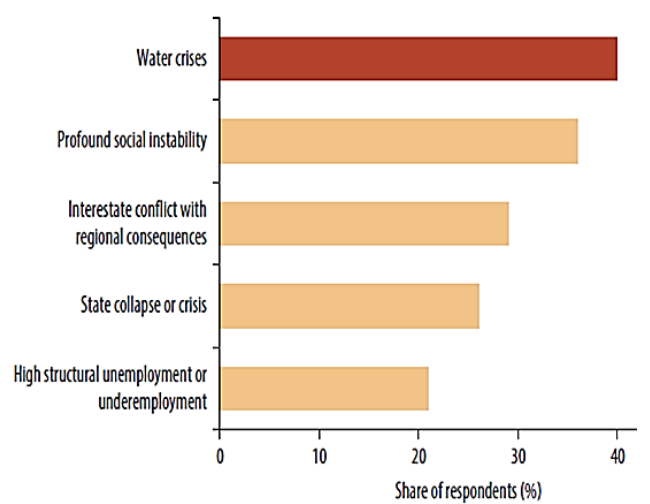

Fig. 1. Water problem is the major risk in the Middle East and North Africa [2]

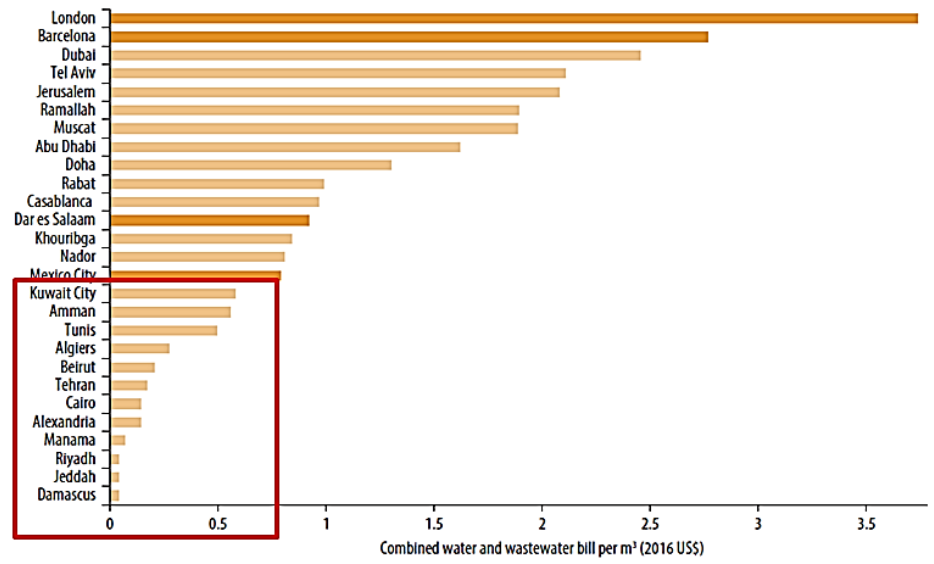

$\square$ Selected cities in Middle East and North Africa $\square$ Selected dities in other regions

Fig. 2. Water and sanitation Bill per cubic meter/USD, in some selected cities in the Middle East, North Africa and other regions [2]

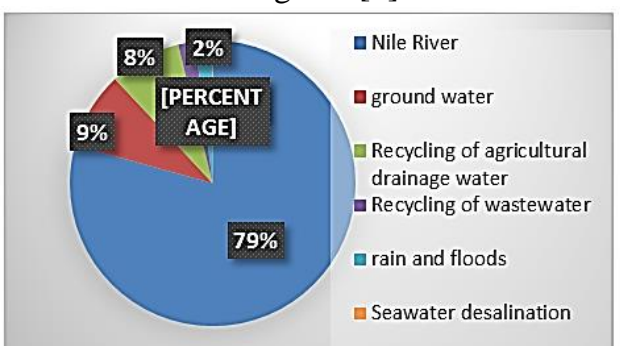

Fig. 3. Available water resources [3]

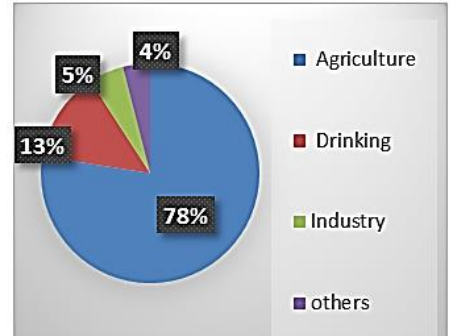

Fig. 4. Water for the different uses of [12]

- An investigation designated for 2 years ago, the consumption of the city with 4 million inhabitants was 1 billion $\mathrm{m} 3$ /day and now it reached 550 million $\mathrm{m} 3$, which is less than $50 \mathrm{~L} /$ day after the announcement of Zero Day in Cape Town [5].

- A study signposted that Canada and United States reduced domestic consumption in $1999-2013$ to $22 \%$ by using water-saving devices [8].

- WordPress investigated the effective measures that can be implemented in the American households to reduce water use in the kitchen and bathroom to replace conventional units with higher wastage modern units or additions easy installation. This decreased water consumption by $45.1 \%$, while savings as a result of the adjustment of certain practices reduced $30.2 \%$ [10]. 
- The Environment Agency of Abu Dhabi with a similar study designated the ratio of $59 \%$ of water by changing some practices and tools to save 410 billion L/year [11].

After reviewing the literature, it was obvious that awareness is an important factor in watersaving. Also, many appliances reduced fresh water waste. This would effectively modify the consumption habits and will contribute effectively to achieve water security in countries.

\section{Problem definition}

The United Nations estimated, in its report [6] on the 11 cities most vulnerable to water disasters, that there is a severe shortage that could be similar to Cape Town by 2025. It further documented that Cairo was the fourth among other countries due to its increased demand, agricultural waste and household waste, where the Nile River is its main fresh water source. Another study was investigating water sufficiency in the Mediterranean countries "Portuguese experience" designated that the use of water-saving devices in bathrooms and kitchens rationalized the consumption to $45 \%$. These devices are influential in addressing water problems [7] .

This encouraged this study to be commenced in order to investigate the implementation of architectural role if any to restrict fresh water abuse by reducing surplus water consumption in new urban communities.

\section{Objectives}

In recent studies the Arab Forum for Environment and Sustainable Development [13], designated that $75 \%$ of a questionnaire tested sample were aware that the per capita consumption rate of Arab countries are the maximum, worldwide. This is attributed to their excessive consumption and lack of rationalization principles [13]. However, no serious effort was initiated. This study was initiated with the main objective of presenting simple and affordable tools to reduce water consumption in new urban communities through the role of architect to restrict fresh water abuse by simple easy adjustments or replacements.

As for the sequential objectives, they are as follows:

- Investigate the role of architects, as community guide that implement the 5R strategy as shown in Fig.5.

- Survey the perception of water problem awareness via a questionnaire; analyze its results to perceive a mental image to the problem and to evaluate the impact of water saving devices and replacements.

- Evaluate behavior changes and replacement of devices to reduce water consumption and preserve them for future generations.

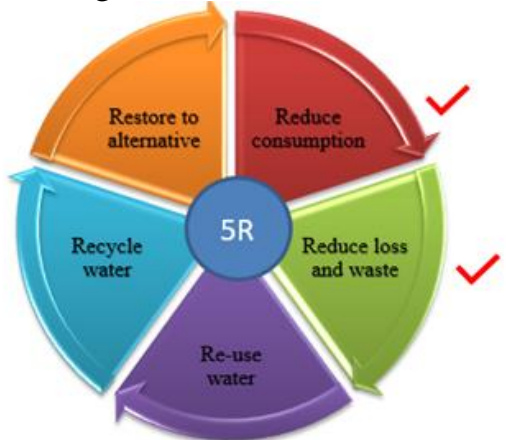

Fig. 5. 5R, Consumption Efficiency in houses [7] 


\section{Hypothesis}

The study put forward some hypothesis, such as:

- Architectures guidance in purchasing taps/mixers in kitchens and bathrooms in new cities contribute in water rationalization.

- New city dwellers have high awareness in choosing taps mixers units due to their high educational level, cultural, economic and lifestyle compared to urban residents.

\section{Methodology}

This study adopts a descriptive analytical methodology to measure and analyze the role of architectural design mechanisms and community awareness in water consumption rationalization for residents in New Cairo.

\subsection{Methods and tools}

The implemented tools were:

- A theoretical study to assemble data in the field of water consumption.

- A questionnaire to survey the awareness of a randomly selected population.

Domestic fresh water is distributed into 2 main portions (i.e. Indoor and outdoor), where this study is restricted to the taps and mixers in kitchen and bathroom; Fig.7. On the other hand, domestic consumption is divided into several parts and is represented by water consumption of taps (i.e. washing hands, shower, kitchen, leaks). This mounts up to $46 \%$ of daily domestic consumption [14]; Fig.8. In case of manipulating these units through a set of habits and alternatives, they can achieve from $22 \%$ to $59 \%$ consumption reduction [8-12], [13].

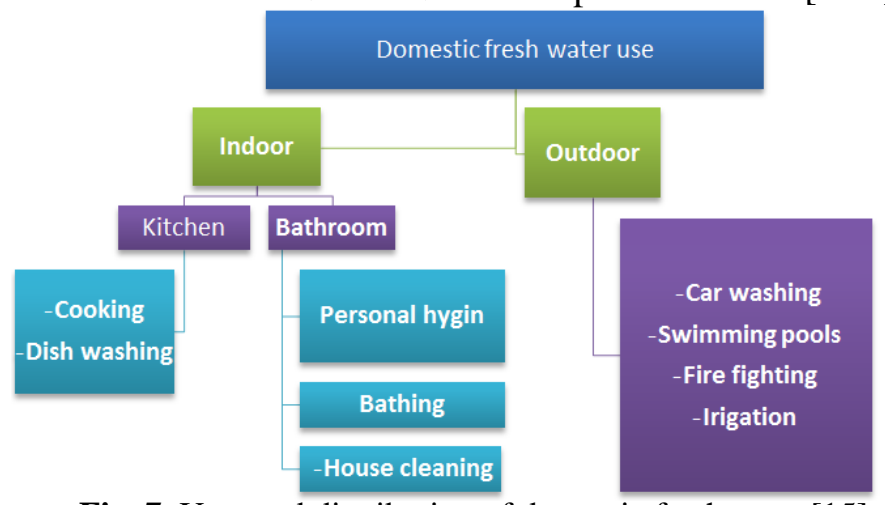

Fig. 7. Uses and distribution of domestic freshwater [15]

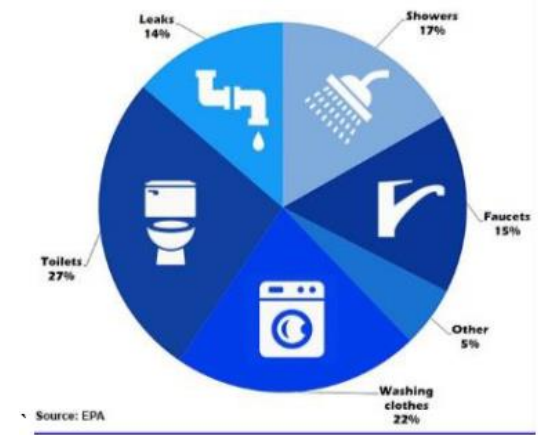

Fig. 8. The proportions of indoor domestic freshwater use [14] 


\subsection{Investigated units}

Mixers and taps were, architecturally, designed to operate with simple smart mechanisms (i.e. units), where their prices range depend on the implemented technology in manufacturing.

Accordingly, this study is focused on investigating a variety of taps that are available on Egyptian market. This is attributed to the fact that the questionnaire will target these units; Fig.9. Tables 1, 2 are provided to compare these types, in terms of operation, cost, advantages and disadvantages.

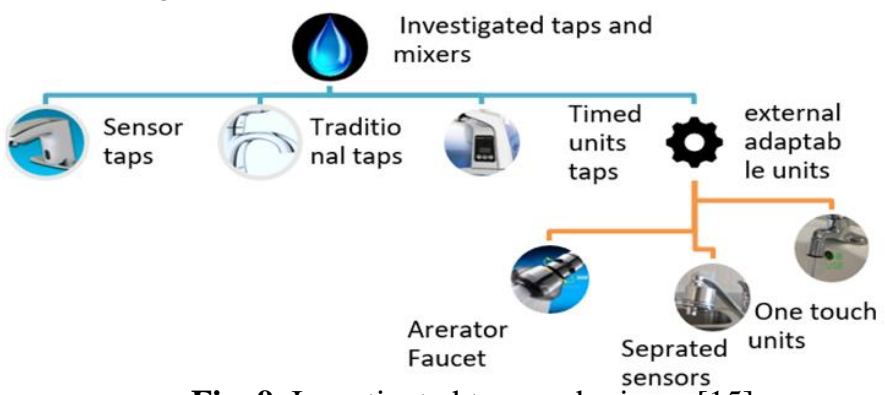

Fig. 9. Investigated taps and mixers [15]

Table 1.

The basic differences of mixers [15]

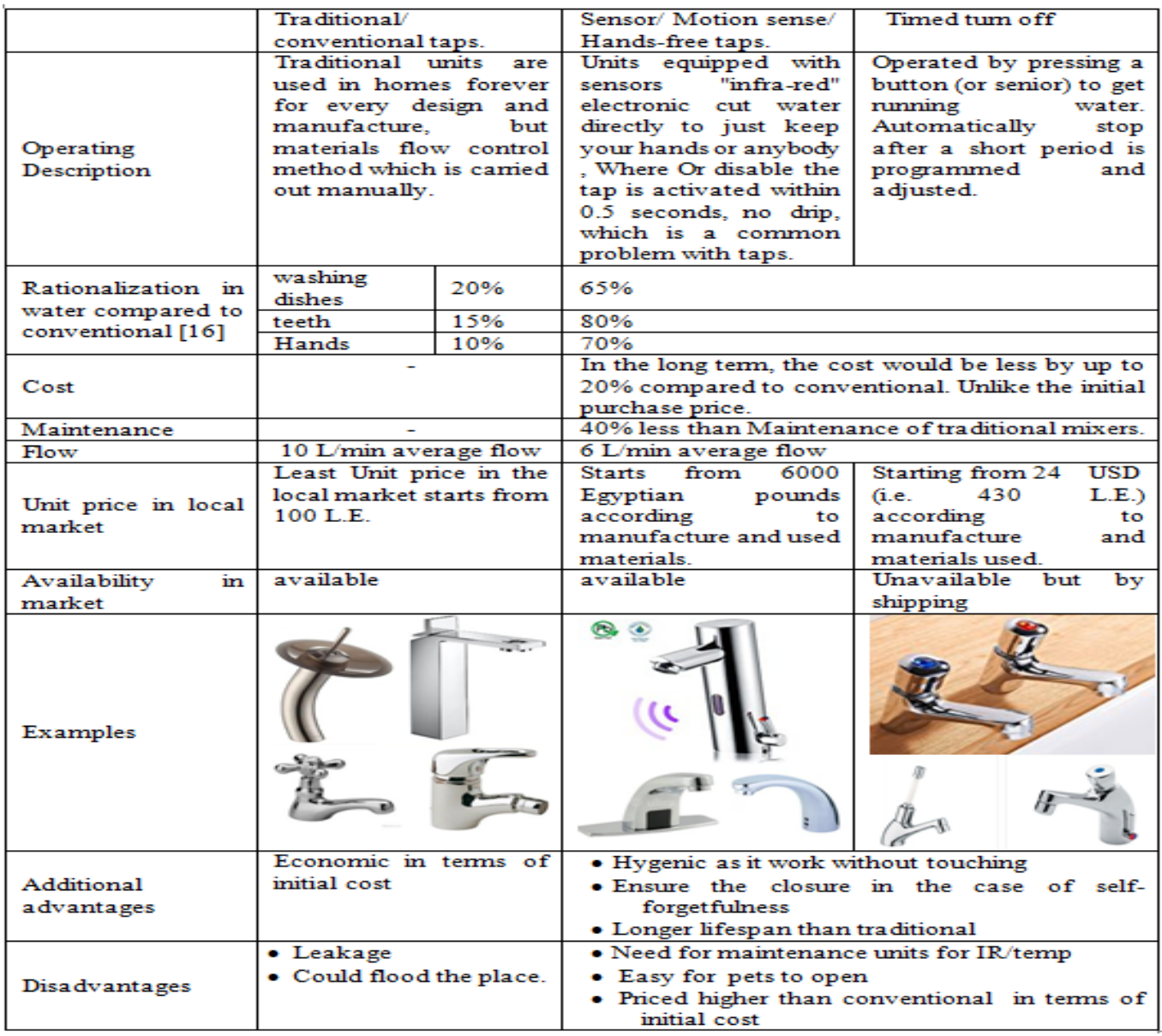


Table 2.

Differences between complementary units fitted to mixers [15]

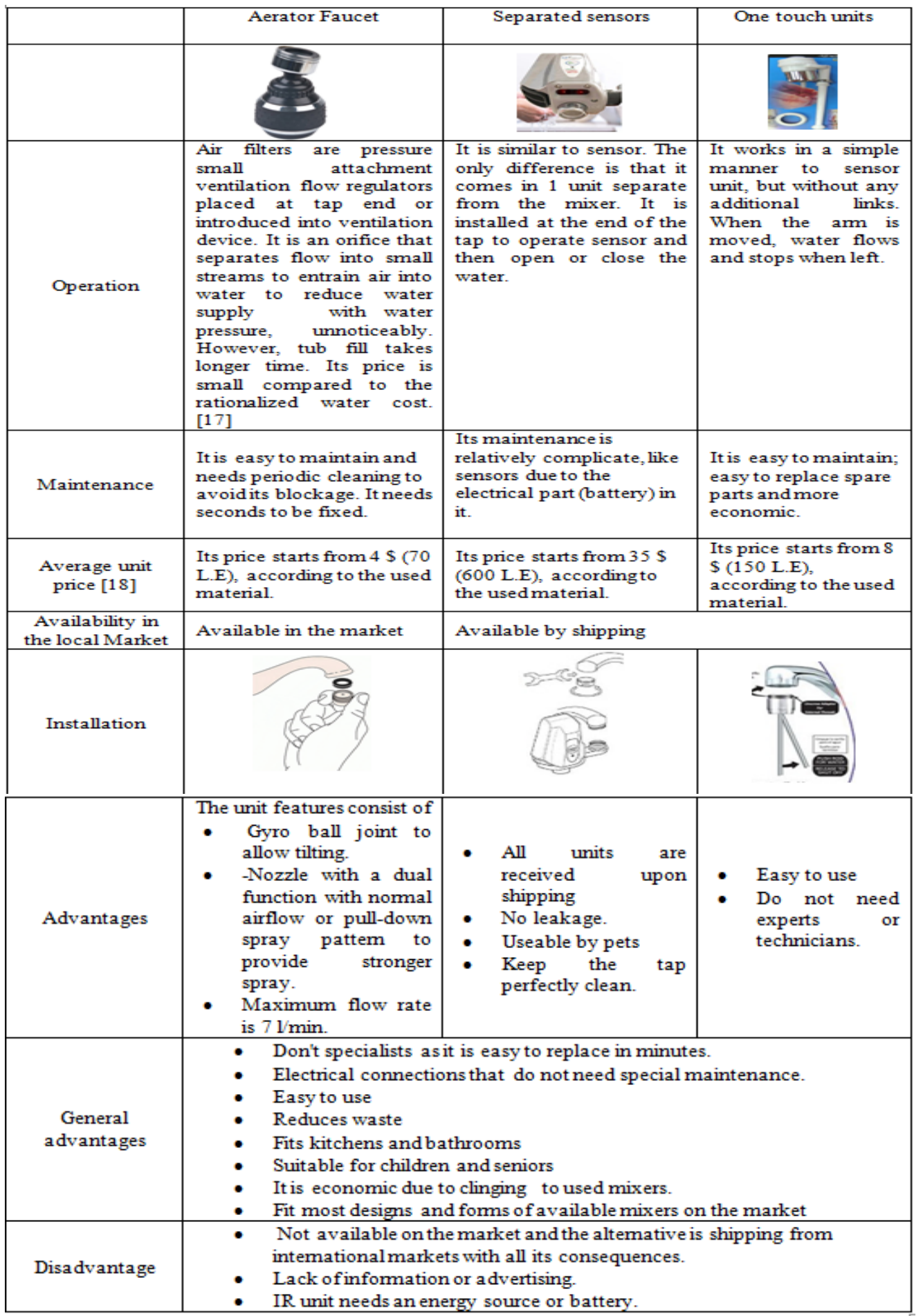


The rate of using tap water in kitchens and bathrooms depends on several factors that were considered in the questionnaire. These factors encompass the following:

- The more the number of living individuals in the unit, the more the consumption rate and dishwashers reduce water consumption up to $25 \%$ [19]

- Seasonal consumption varies. Winter consumption increases due to the waiting of warmer water to wash face, hands, ablution, bathing and dish washing. Accordingly, the questionnaire encompassed an inquiry about utilization rates from March to June 2018 [20]

- Receiving advice from an architect/ecosystem consultant during the construction process might affect the consumption rate.

- The economic level of the residence will affect their purchasing power to modern saving units.

The present study focused on the role of architect, the economic level and education level in selecting mixers and taps to raise their performance with/without being replaced. In addition, a statistical analysis was performed to survey the random population perception to water saving units and the role of architects to implement design mechanisms to enhance the water consumption behavior.

The electronic forms were distributed among a random population in the different segments of society. After receiving the answers, a statistical analysis was carried out using SPSS 22 "Statistical Package for the Social Sciences".

\section{Results and discussion}

The questionnaire was received from the random sample (100 participants) within 3 months. Responses were analyzed, in terms of three key phases:

- During the First Phase, the participants were categorized into categories.

- All through the Second Phase, calculations were achieved to determine the rates of flow, based on the received questionnaire responses.

- Throughout the Third Phase, a statistical analysis was achieved by implementing SPSS "Statistical Package for the Social Sciences" to study the effect of the variables.

\subsection{Phase 1: categorizing the participants}

The participants were categorized to find out the following:

- The age of 30 to 40 and 20 to 30 recorded the major portion of participants (i.e. $60 \%$ ), which indicated that it is evident that their unawareness is doubtful, and their experience is questionable.

- Academic level (i.e. Bachelor) designated $75 \%$ of the participants, Lower education designated $1.5 \%$.

Fig.10 provides the proportions of age groups, housing category, average family members and educational level of participants. 


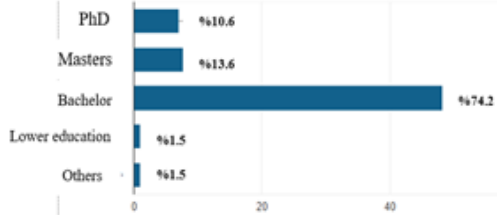

1. Participants educational levels

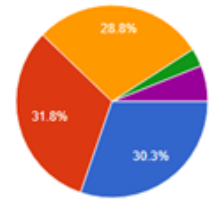

2. Age distribution of participants

Fig. 10. Participants' distribution [15]

Based on the results, it was clear that:

- The traditional taps or mixers with manual flow control were $98 \%$ of all devices in services area for the tested sample.

- $60 \%$ of the sample confirmed the absence of any consultant architect or interior designer in selecting or advising of water saving mixers.

- The sample indicated that the cost then shape dominates their choice. Only $10 \%$ were concerned about water consumption.

- With the aid of the electronic questionnaire responses, videos and info graphs, the importance of water conservation was elaborated to indicate:

- $90 \%$ of the participants confirmed the importance of water scarcity problem data which covered in the form, and the importance of architectural advice to reduce the consumption rates.

- $48 \%$ of the sample willing to replace traditional mixers with water-saving types (i.e. restoration and replacement (higher cost).

- $60 \%$ agreed to buy peripherals to upgrade existing mixers without replacement, in case of availability on market with reasonable cost (lower cost); Fig.11.

- Only $34 \%$ of the professional so as architects were aware of water rationalization and sometimes they provided assistance, in that direction, to their clients.

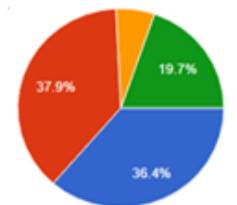

1-Selecting mixers

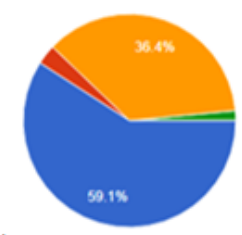

3-Acceptance to purchase complementary units.

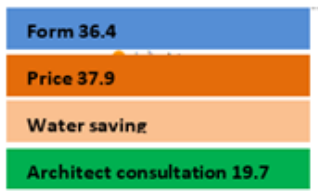

\section{Yes $\mathbf{5 9 . 1}$}

No 4.5

Neutral 36.4

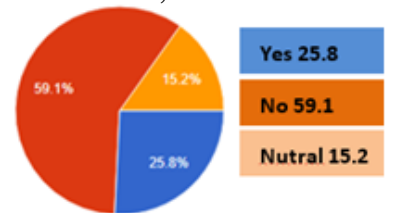

2- The Architect role

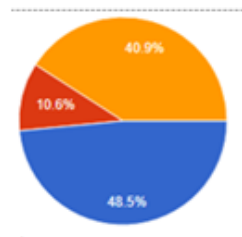

\section{Yes 48.5}

No 10.6

Neutral 40.9

4-Acceptance to replace traditional mixers.

Fig. 11. Perception of participant in the questionnaire [15]

\section{2. phase 2: calculate of flow rates}

A rough measurement process was achieved before and after replacement or adjustment with the architecture design mechanisms. This was achieved to determine the flow rate and the water consumption in the area of study, where the number of family members and age were considered.

The results were tabulated in Table 3 . It indicated that the daily water loss rate decreased. 
Table 3.

Random sample consumption rates based on the questionnaire [15]

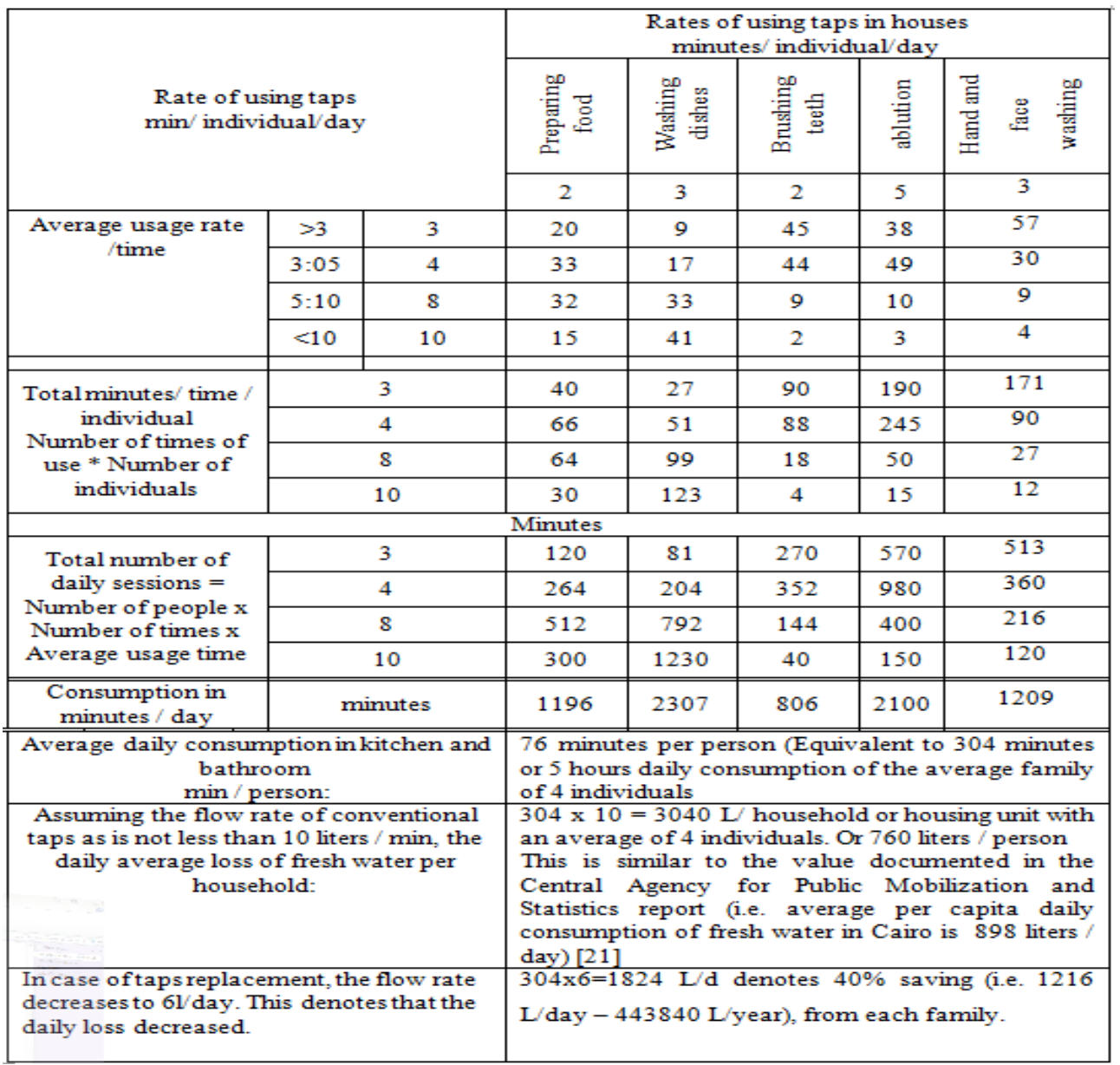

\subsection{Phase III: statistical analysis "SPSS"}

Data was analyzed statistically by SPSS 22 software, by implementing the Chi-Square technique to determine variable indicators. It was designated that a relationship exists at $\mathrm{P}<0.05$. In addition, a analysis was performed to determine data -variables correlation. The variables were age, type of housing, education, the role of the architect, selection criteria, selection of mixers, mixers replacement, adding supplementary units (architecture mechanism) to rationalize water. The software indicated that certain variables were of obvious influence; Table 4, Fig.12. 
JES, Assiut University, Faculty of Engineering, Vol. 47, No. 2, March 2019, pp. 250-264

Table 4.

The results of Chi square among variables [15]

\begin{tabular}{|c|c|c|c|c|}
\hline \multicolumn{2}{|c|}{} & $\begin{array}{c}\text { mixer } \\
\text { selection }\end{array}$ & $\begin{array}{c}\text { mixer } \\
\text { replacement }\end{array}$ & $\begin{array}{c}\text { using } \\
\text { additional } \\
\text { units }\end{array}$ \\
\hline \multirow{2}{*}{ Variables } & Sig. & 0.044 & 0.323 & 0.201 \\
\hline \multirow{2}{*}{ Education } & Value=R & 17.331 & 6.974 & 8.541 \\
\cline { 2 - 5 } & Sig. & 0.605 & 0.502 & 0.873 \\
\cline { 2 - 5 } Role of Architect & Value=R & 10.130 & 7.323 & 3.820 \\
\cline { 2 - 5 } & Sig. & 0.010 & 0.814 & 0.883 \\
\hline \multirow{2}{*}{ Age category } & Value=R & 16.906 & 1.573 & 1.168 \\
\cline { 2 - 5 } & Sig. & 0.019 & 0.291 & 0.232 \\
\hline
\end{tabular}

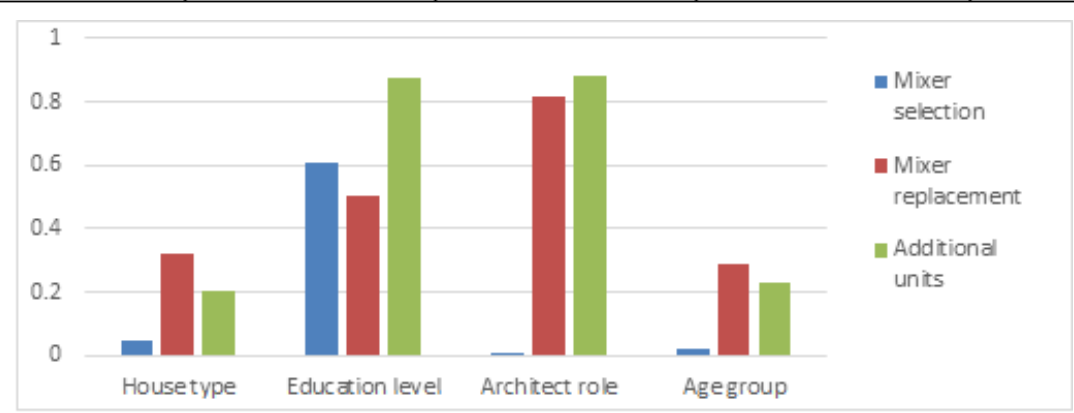

Fig. 12. Chi square test for selected variables [15]

Table 5.

Linear relations between tested variables and their dominancy [15]

\begin{tabular}{|c|c|c|c|c|}
\hline \multicolumn{2}{|c|}{ Linear Coloration Strength } & mixer & mixer & $\begin{array}{c}\text { using } \\
\text { additional }\end{array}$ \\
\hline \multirow{2}{*}{ House type } & Sig. & 0.056 & 0.360 & 0.259 \\
\hline & Strength & Moderate linear & - & - \\
\hline \multirow{2}{*}{ Education } & Sig. & 0.796 & 0.589 & 0.938 \\
\hline & Strength & - & - & - \\
\hline \multirow{2}{*}{ Role of Architect } & Sig. & 0.015 & 0.799 & 0.937 \\
\hline & Strength & Moderate linear & - & - \\
\hline \multirow{2}{*}{ Age category } & Sig. & 0.004 & 0.440 & 0.399 \\
\hline & Strength & Strong linear & - & - \\
\hline
\end{tabular}

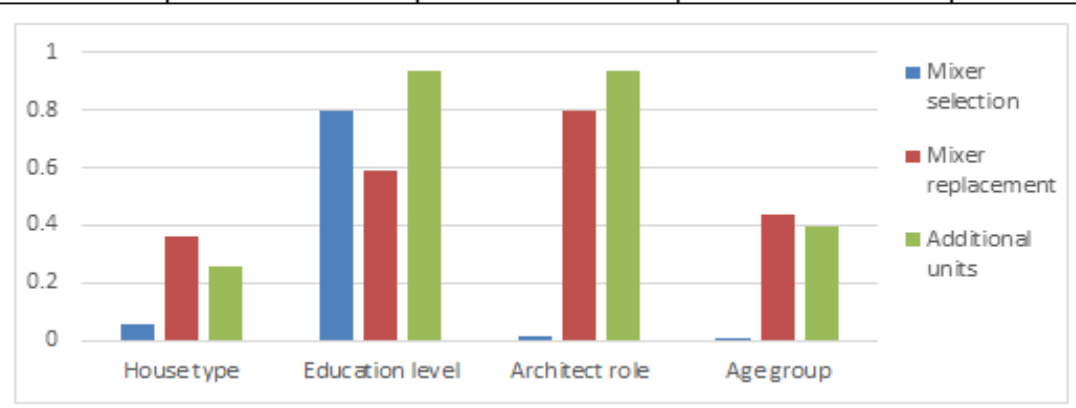

Fig. 13. linear coloration for selected variables [15]

The chi square test indicated that: 
Ebtehal Galal El Deen Mohamed, The role of the architect in choosing sustainable units to .....

- The housing type and selection of mixer was found to the strongest at a Residual $>1.96$ between over-average house type and choosing mixers that saves water to reduce water bills, While, it was clear that their price was the choice factor for luxury housing for social look without considering saving water or money Table6.

\section{Table 6.}

Crosstab for housing type

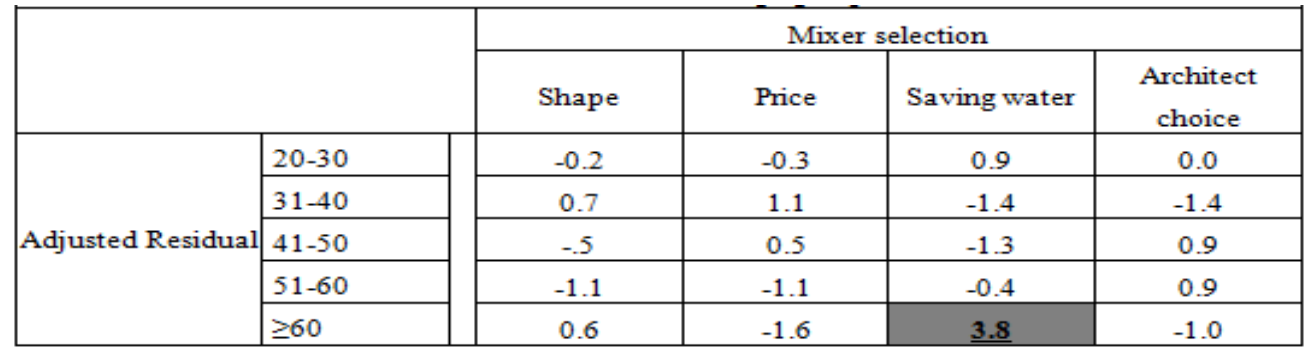

- The role of architect and selection of mixers was found to the strongest at a Residual $>1.96$ for the shape of mixer not its functionality or saving features and tis reflect the negative role of architecture practice in the water saving section in this case study Table7.

\section{Table 7.}

Crosstab for the architect role

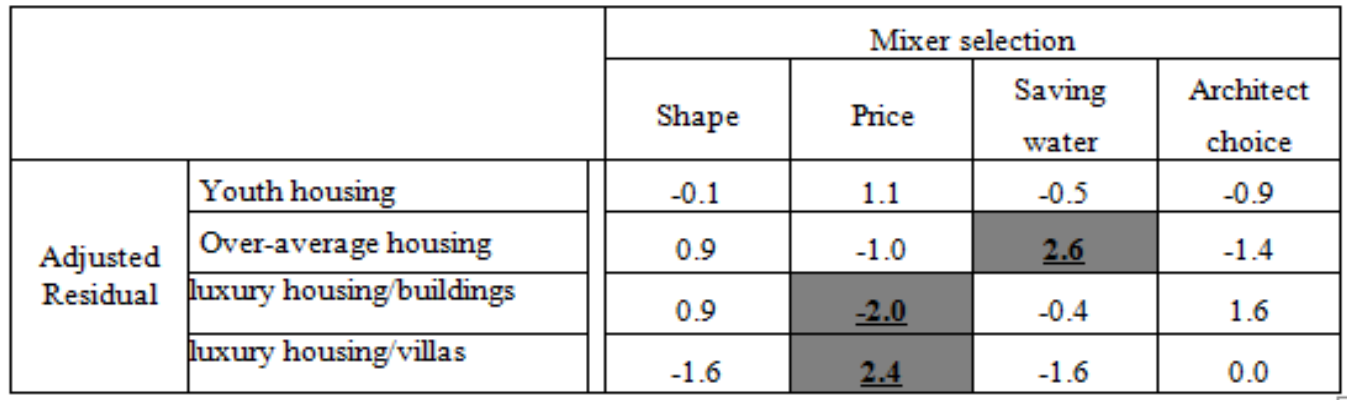

- The age category and selection of mixer was found to the strongest at a Residual>1.96, where the selection, at ages of (higher than 50) considered the mixer functionality and water saving and this reflect the water consumption awareness Table 8 .

Table 8.

Crosstab for Age group

\begin{tabular}{|c|c|c|c|c|c|}
\hline & & \multicolumn{4}{|c|}{ Mixer selection } \\
\hline & & Shape & Price & Saving water & $\begin{array}{c}\text { Architect } \\
\text { choice }\end{array}$ \\
\hline \multirow{3}{*}{ Adjusted Residual } & Yes & -1.9 & -0.3 & -1.2 & 3.3 \\
\hline & No & $\underline{\underline{2.0}}$ & 0.6 & 0.7 & 0.0 \\
\hline & Neutral & -0.5 & -0.6 & 0.6 & 0.9 \\
\hline
\end{tabular}

- Although there was no clear correlation between other factors, but some remarks were common among them Table 5, Fig.13. These were: 
- The effect of over-average house type accepted change to water saving units and to replace them entirely with least waste units, indicated their awareness and desire for rationalization at this category.

- Educational level had a great influence on the replacement of mixers, which indicated their thinking pattern to realize facts and analyze results.

- Older age group agreed quickly to the replacement idea due to their longer experience. They recognized the magnitude of the problem and need for rapid intervention.

- As for the coloration indicator, it was found to be a linear correlation, where a strong correlation was evident between the effects of age on mixer selection, moderate coloration between housing type/ the architect role on mixer selection, while no obvious correlation was found among other variables. This emphasized Chi- Square results; table (5).

Hence, these factors did not affect properly the understanding of the depth of the problem, which calls for raising the level of alert in the development of the field of environmental awareness at all levels and in all disciplines.

\section{Conclusions and recommendations}

The relation between the architect and mechanical engineer or any other expert in building field is a well-known relationship and does not diminish the role of any of them, each has his own tasks and challenges within the team to ensure the success for the project. But remains the architect is the general coordinator of all specialists and the team's Maestro, he/she is the link between other's work and the end user. Hence, the interior configuration will remain the task of the architect, his/her role is the most important and explained here in the paper to achieve sustainability, beauty and reduce fresh water abuse especially in new urban communities. But as shown in the paper there was no significant role of the architect to save water in new communities neither policies nor architectural practice. This role must be supported and activated in planning, making polices, building regulations, and dealing with end users by sustainable waters saving advices, which is marginalized due to lack of expertise in the planning system or lack of knowledge and awareness of the water problem at user level.

In order to reduce the water consumption, government should invest in water infrastructure, information systems and institutions to go beyond the traditional approach in managing scarcity. City government offices and localities should also encourage policies related to water conservation and efficient use as used in Abu Dhabi (i.e. Pearl rating system and landscaping to reduce water consumption to a minimum) and awards citizens and institution who achieved maximum saving [22].

In brief, it is worthy to mention that water conservation is the most cost-effective way to environmental safety by reducing pressure on lakes, rivers, reservoirs, wastewater treatment facilities. Additionally, this would help in protecting the environment by reducing thermal emission and saving more country resources to the future generation.

For future studies, related ideas could be investigated:

- Adopt using central heaters in new communities which designed with HWRS "Hot Water Recirculation Systems" by mechanical engineer with cooperation with architects to save more water and energy. 
- On large scale, evaluate local products in terms of water saving and launch initiatives in collaboration with local bodies and institutions with different engineering specialists to provide trademarks and franchise programs could be more significate in the next years.

\section{REFERENCES}

[1] "The World Bank," Available: http://www.albankaldawli.org/ar/topic/water/overview. [Accessed 132 2018].

[2] "MENA DEVELOPMENT REPORT, Beyond Scarcity Water Security in the Middle East and North Africa," International Bank for Reconstruction and Development, 2018.

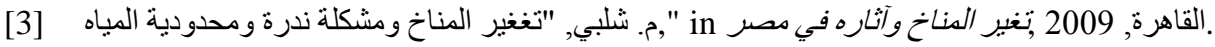

[4] "JMP- World Health Organization," [Online]. Available: https://washdata.org/data. [Accessed 122 2018].

[5] "BBC," 2 2018. [Online]. Available: http://www.bbc.com/news/world-africa-43047833.

[6] "BBC," [Online]. Available: http://www.bbc.com/news/world-42982959. [Accessed 2 2018].

[7] S.-A. A. a. P.-R. C., "The importance of water efficiency in buildings in Mediterranean countries. The Portuguese experience," INTERNATIONAL JOURNAL OF SYSTEMS APPLICATIONS, ENGINEERING \& DEVELOPMENT, vol. 5, no. 1, pp. 17-24, 2011.

[8] K. Retter, "Consumer Reports," 2015. [Online]. Available: http://consumersunion.org/2015/06/stop-wasting-money-start-saving-water/. [Accessed 2 2018].

[9] "Sesam Business Consultants," [Online]. Available: http://www.sesamuae.com/muscat/presentations/Toufic\%20Halabi,\%20Grohe.pdf. [Accessed 3 2018].

[10] . Z. Shahzeen and D. Benjamin, "Enviroment. scince and policy for sustainable development".

[11] " Water fact sheet," Heroes of the UAE, Abu Dabi, 2018.

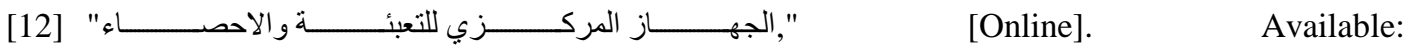
http://www.capmas.gov.eg/Pages/Publications.aspx?page_id=5109\&YearID=19630. [Accessed 2 2018].

[13] N. Saab, "Consumption Patterns in Arab Countries. AFED Public Opinion Survey," Arab Forum for Environment and Development., 2015.

[14] S. F. Moahmed, "Reuse of graywater in Egypt: Reality and hope," in Al Azhar's 14th International Conference on: Engineering, Architecture \& Technology, Cairo, 2017.

[15] الباحث, 2018.

[16] "Autotaps," [Online]. Available: http://www.autotaps.com/sensor-taps-facts-and-charts.html. [Accessed 3 2018].

[17] "Savewatersavemoney," [Online]. Available: https://www.savewatersavemoney.co.uk/waterefficiency-tips-advice/view/120/tap-aerators---how-do-they-work.html. [Accessed 125 2018].

[18] "Amazon," [Online]. Available: https://www.amazon.com/ref=nav_logo. [Accessed 125 2018].

[19] "Study on water efficiency standars," European Commission (DG ENV), Paris, 2009.

[20] F. M. ,. D. B. A.M. Fidar, "Performance evaluation of conventional and water saving taps," Science of the Total Environment, no. 541, p. 815-824, 2016.

[21] " Built Environment Deprivation Indicator (BEDI)," 10tooba, [Online]. Available: http://10tooba.org/bedi/en/safe-water/. [Accessed 3 2018].

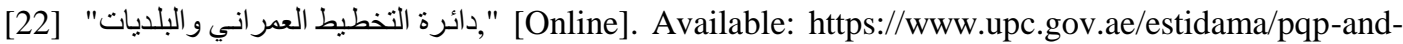
ica/estidama-villa-product-database/water-fixtures-and-fittings. 
دور المعماري في اختيار الوحدات المستدامة للحد من إساءة استخدام المياه

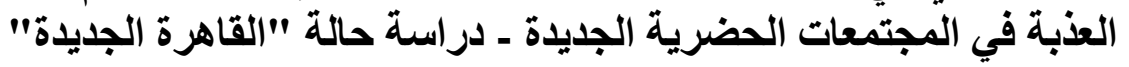

الملخص العربى:

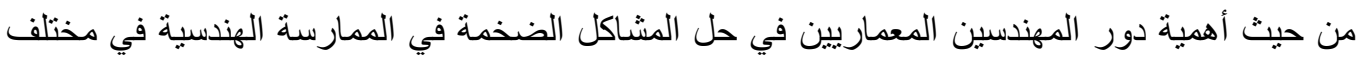

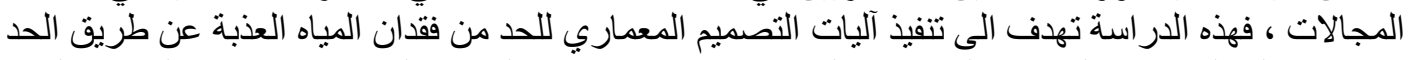

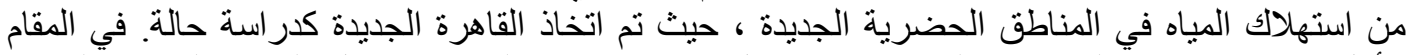

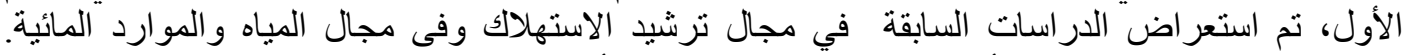

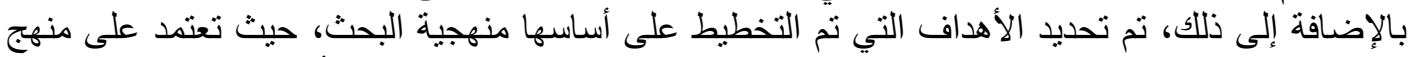

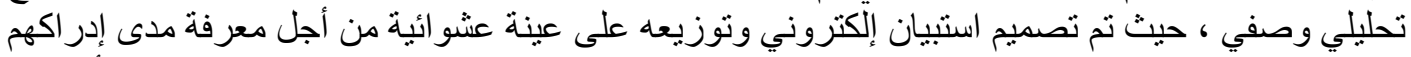

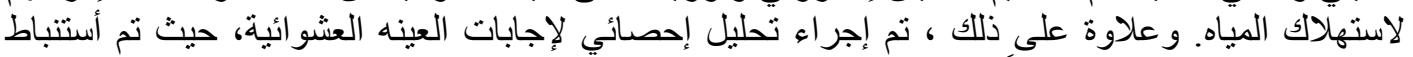

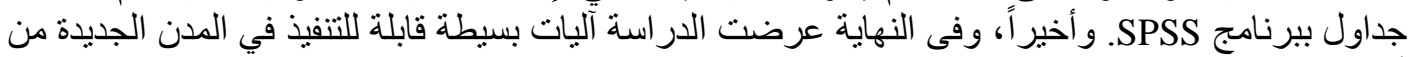

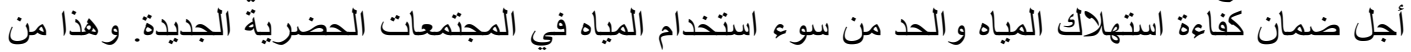

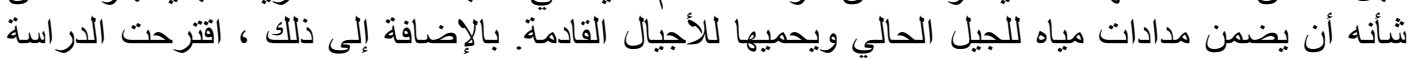

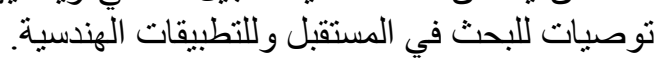

